\title{
Construction Professionals' Perspectives on Drivers and Barriers of Sustainable Construction
}

\section{Abstract}

With the associated environmental challenges and unsustainable patterns of construction, there is also notable awareness and willingness among the state bodies to adopt sustainability measures and practices in Kazakhstan. This study explores the drivers of, and barriers inhibiting the adoption of sustainability paradigm in the construction context of Kazakhstan. The drivers and barriers were validated through the survey and structured workshop with the construction professionals to ensure their relevance to the local context, which were then ranked according to their levels of influence through the lens of the industry professionals in Kazakhstan. Delphi technique was the last stage before consolidating the specified lists. Stakeholder opinions were then consolidated to develop a context-oriented Decision Support System. The findings reveal that addressing environmental issues is vital to increase the level of sustainability leading to the more efficient use of construction materials and resources. Various social aspects are also found to be driving forces for the effective adoption of the SC concept. On the other hand, a great portion of SC barriers is related to economic aspects, which are followed by government as well as awareness and education related barriers. The findings are hoped to contribute to the body of knowledge in terms of drivers of, and barriers to SC in developing countries, particularly in Central Asian countries due to similarities in context. The findings may also be useful for the construction forefront players seeking ways to improve sustainability performance of the construction industry.

Keywords: Kazakhstan; sustainable construction; drivers; barriers.

\section{Introduction}

Rapid increase in urbanization in developing countries led to a boom in construction activities; hence, increased the detrimental impact of the sector on the environment, society and economy (Durdyev et al. 2018a). Reportedly, the construction industry is responsible for a considerable amount of energy and resource consumption (Safinia et al., 2017). Recent studies reported that the industry is responsible for $16 \%$ of water, $25 \%$ of timber and $40 \%$ of raw materials as well as 32\% of total energy consumption (Serpell et al. 2013; EIA, 2012). Additionally, the industry is responsible for about $40 \%$ of waste generation and one-third of carbon emissions, which is clear evidence of the devastating impact on the environment, society and economy (Serpell et al. 2013). The adoption of a sustainability paradigm in the construction sector is therefore crucial, as it aims at reducing the industry's harmful impact, 
and has attracted an increasing attention from the stakeholders and decision-makers of both private and public sectors of countries regardless of their socio-economic status (Sev, 2009).

Anecdotal evidence shows that, despite several initiatives, the situation in Kazakhstan is not that much different and yet, the uptake of SC is still moderate. Several studies reported that a lack of knowledge and awareness of the SC concept leads to the idea being disregarded by construction professionals (Sev, 2009; Abidin, 2010). Moreover, perceived higher cost of sustainable practices and lack of promotional initiatives by the authorities are reported to be hindering factors of SC (Ahn et al. 2013). In light of reported hindering factors, the adoption of SC practices has been driven by several factors in various countries (Durdyev et al. 2018a; Whang and Kim, 2015). Thus, SC practices have received broad attention from the stakeholders worldwide (Sev, 2009; Qi et al., 2010; Berardi, 2013; Durdyev et al. 2018b). Despite the existing reported studies on drivers of, and barriers to implementing SC, the topic has yet to match the deserved attention within developing countries. Moreover, due to the uniqueness of each country's social, economic and political environment, there is a need for country-specific diagnosis. In this regard, through the lenses of the construction professionals this study aims to evaluate the factors that will drive implementation and barriers inhibiting SC in Kazakhstan. By construction professionals this study understands It is hoped that the findings of this study uncover the most prominent drivers of, and barriers to SC adoption through the lens of developing country practitioners for further efforts of efficient resource allocation.

\section{Sustainable construction (SC): Overview}

The construction industry plays a crucial role in providing basic infrastructure and shelters to society as well as stimulating demand for other sectors with which it has direct and indirect linkages (Durdyev and Ismail, 2016). However, the construction practices that have been implemented across the globe have led to severe depletion of natural resources, economic instabilities and loss of cultural heritage (Kibert 2013). It has been reported that the impact of construction practices across the globe accounts for $40 \%$ of atmospheric emission, $42 \%$ of energy use, $30 \%$ of raw materials use, $25 \%$ water use and $25 \%$ of waste generation (Zolfani et al. 2018). These problems have become more severe, given the rapid urbanization and growth in population, particularly in developing countries (Durdyev et al. 2018b). As such, these severe effects of the construction industry have attracted the attention of national governments and forefront construction players (Martek et al. 2019). 
SC defined as "ability to create and operate a healthy and resource-conscious built environment" (Kibert, 2013), was first introduced to mitigate the building sector's detrimental impact on the environment. Consequently, significant changes have been experienced in project delivery methods (Kibert, 2013). SC was initially perceived to be concerned only with environmental protection (Sev, 2009). However, being one of the major contributors of a national economy and provider of basic infrastructure to society, other pillars of sustainability, such as economic and social, cannot be disregarded. In other words, further integration and a holistic approach are required to balance the main pillars of the sustainability paradigm (Du Plessis, 2002). A further recommendation is considering the benefit of sustainability upon the triple-bottom-line, rather than the traditional measures of cost, time and quality (Huovila and Koskela, 1998).

\section{Identification of drivers and barriers}

Despite the slow progress, the certification (LEED, BREAM) of thirty-nine buildings in Kazakhstan shows sufficient evidence of stakeholders' interest and driving forces (drivers) towards SC development (The Green Building Information Gateway (GBIG), 2018). These drivers have also been defined as a response to balance environmental, economic and social issues within the construction practices (Sev, 2009). Of note, the dearth of studies in the local context necessitated the acknowledgement of the international context on SC to identify potential drivers and barriers. Thus, a number of studies have documented various drivers in line with country- or region-specific priorities, which are believed to influence stakeholders' decisions on implementing SC practices (Qi et al. 2010). For example, Hakkinen and Belloni (2011) report a study from Finland, where development of the awareness among the clients about the benefits of SC, adoption of methods for SC requirement management, the mobilization of SC tools, the development of designers' competence and team-working are the most significant drivers of SC. Serpell et al. (2010) found that corporate image, cost reduction, company awareness, regulations, client demand, market differentiation and suppliers are the most influencing drivers in Chile. Resource conversation, improvement in indoor environment quality, energy conservation and waste reduction are reported as the most significant drivers of SC in the United States (Ahn et al. 2013).

Notwithstanding the well-known benefits of SC practices, there is a need for a considerable amount of time and effort for their widespread adoption, particularly in developing countries where the existence of barriers make the adoption "impossible or 
unprofitable" (Evans, 2006). In this regard, various studies have reported the barriers to implement SC practices in the context of different countries. The vast majority of the studies (Hakkinen and Belloni 2011; Ahn et al. 2013; Durdyev et al. 2018a, b; Ogungbile and Oke 2019; Rock et al. 2019), particularly from developing countries, reported that concerns with the cost premium of SC and lack of knowledge and awareness are the most significant barriers, which ultimately lead to the reluctance to implement the SC concept.

No doubt that SC will significantly improve economic and social conditions of people as well as reduce the environmental impact of the industry (Durdyev et al. 2019). In-depth review of the sustainability context reveals the similarity in the drivers and barriers of SC adoption. However, sui generis socio-economic conditions of Kazakhstan require a particular diagnosis of the drivers and barriers according to the context where the construction industry is operated. Moreover, this diagnosis, due to contextual similarities, is hoped to guide the construction decision makers in other Central Asian countries. Thus, the outcomes of a comprehensive review of the context, which are drivers of, and barriers to SC, are presented by Tables 1 and 2, respectively.

Table 1: Drivers of SC

\begin{tabular}{|c|c|c|}
\hline & Drivers & References \\
\hline \multirow{8}{*}{ 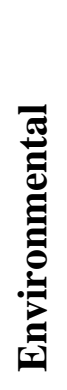 } & Energy efficiency/conservation & Ahn et al. (2013) \\
\hline & Material/resource efficiency & Durdyev et al. (2018a) \\
\hline & Water efficiency & Abidin and Powmya (2014) \\
\hline & Efficient use of land & Manoliadis et al. (2006) \\
\hline & Waste reduction/management & Whang and Kim (2015) \\
\hline & Atmosphere & Durdyev et al. (2018a) \\
\hline & Indoor environmental quality/comfort & Manoliadis et al. (2006) \\
\hline & Preserving the ecology & Akadiri et al. (2012) \\
\hline \multirow{6}{*}{ 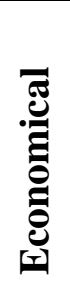 } & Competitive construction industry & Wong et al. (2010) \\
\hline & Life cycle cost & Ogungbile and Oke (2019) \\
\hline & Affordable construction material & Akadiri et al. (2012) \\
\hline & Support of national economy & Li et al. (2013) \\
\hline & Commercial viability & Whang and Kim (2015) \\
\hline & Improvement in industry image/reputation & Serpell et al. (2013) \\
\hline \multirow{5}{*}{ 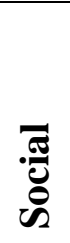 } & Enhanced health and safety & Whang and Kim (2015) \\
\hline & Collaborative working environment & Li et al. (2013) \\
\hline & Preserving culture/heritage & Sev (2009) \\
\hline & Secure industry & Akadiri et al. (2012) \\
\hline & Community friendly industry & Ahn et al. (2013) \\
\hline
\end{tabular}

Table 2: Barriers to SC

\begin{tabular}{|l|l|}
\hline Barriers & References \\
\hline Lack of promotion by government & Durdyev et al. (2018b) \\
\hline Lack of regulations and policies & de Souza Dutra et al. (2017) \\
\hline
\end{tabular}




\begin{tabular}{|l|l|}
\hline Lack of government incentives & Zhang et al. (2012) \\
\hline Lack of enforcement & Williams and Dair (2007) \\
\hline High cost of sustainable options & AlSanad (2015) \\
\hline Longer payback periods & Ahn et al. (2013) \\
\hline The priority is given to economic needs & Durdyev et al. (2018a) \\
\hline Lack of financial incentives & Luthra et al. (2015) \\
\hline Limited understanding from stakeholders & Abidin (2010) \\
\hline Knowledge on benefits of sustainable is limited & AlSanad (2015) \\
\hline Knowledge on sustainable technologies is limited & Ahn et al. (2013) \\
\hline Lack of green suppliers and limited information & Gou et al. (2013) \\
\hline Lack of demonstration projects & Potbhare et al. (2009) \\
\hline $\begin{array}{l}\text { Lack of education and training for construction } \\
\text { professionals }\end{array}$ & Gou et al. (2013) \\
\hline Lack of competence in sustainability & AlSanad (2015) \\
\hline Lack of professional capabilities/designers & Durdyev et al. (2018a) \\
\hline $\begin{array}{l}\text { Less priority is given to sustainability during the bidding } \\
\text { stage }\end{array}$ & OECD (2015) \\
\hline Lack of clients' interest & Williams and Dair (2007) \\
\hline Reluctance to shift from the conventional methods & AlSanad (2015) \\
\hline
\end{tabular}

\section{Methodology}

Prioritising of the identified drivers and barriers for a developing country context is a challenging task since it is quite likely as one can get significantly different opinions from different stakeholders on the priorities for indicators compared. No commonly agreed method of assessing the stakeholder opinions has been recognized yet, however the process of collecting, analysing, prioritising, and consolidating the drivers and barriers of sustainability performance information in order to support better management decisions are addressed in most of the above mentioned literature. As result, a separate body of literature has developed on the assessment of stakeholder opinions (e.g. prioritisation of drivers and barriers of sustainability) using different procedures and methodologies (Durdyev et al, 2018; AlSanad 2015; Martek et al 2019, Ametepey et al., 2015, Atanda, 2019, Luiz et al., 2018, Kamari et al., 2017, Hugé et al., 2010, Okoli and Pawlowski, 2004; Hurmekoski et al., 2018). They perform their evaluations in numerous ways by underlining the importance of stakeholder theory by considering a broader range of stakeholders' expectations.

This study adopts a stakeholder opinion poll pyramid (SOPP) method, which is structured according to a combined approaches used in a similar way by Atanda (2019), Luiz et al.(2018), Kamari et al. (2017) and Hugé et al.(2010).The procedure steps were as follows: (i) extraction of the sustainability drivers and barriers from the literature pool; (ii) initial preselection, sorting and analysis of the parameters to be assessed by the experts; (iii) obtain 
stakeholder grading on each parameter using a quantitative scale by employing a structured workshop and a survey, and finally vi) consolidation of all information obtained.

Firstly, all potential drivers and barriers were identified through extensive review of literature and sent to the international panel of experts (IPE) (from New Zealand, Norway, Turkey, and Kazakhstan) for their review. This literature survey also showed that the majority of the research studies focusing on awareness, drivers, actions, and barriers of SC utilized a survey based assessment or participation-orientated creative workshops to assess stakeholder opinions (Durdyev et al, 2018; AlSanad 2015; Martek et al 2019, Ametepey et al., 2015). Afterward, all the identified items were validated with the construction professionals to ensure the relevance of the drivers and barriers to the local context through a structured workshop and a survey study, which aimed to eliminate the negative group effects associated with the workshop (Hurmekoski et al., 2018).

The survey questionnaire method was deemed to be one of the most useful tools to obtain the opinions of a large number of construction industry professionals regarding the subject matter. The questionnaire length was chosen to be optimal for 5-7 minutes engagement time, questions were designed to be straightforward and the answers were designed in such a way that the data could be converted into sensible categories and values for analysis (using Likert scale ranking the answers from 1 to 5). The flow and type of questions, the guidelines for the survey as well as its confidential nature were very important aspects to take into account in the survey design process. As a result, the survey had 44 questions, 38 of which were related to drivers and barriers (Tables 3 and 4), 4 were demographics related (Table 5) and two were open-ended for any additional items that were potentially missed in the survey. Approximately 300 validated construction industry related professionals from across Kazakhstan received the link to the survey and 62 responses were collected. The relatively low response rate is explained by the general trend in society where people are not very interested in engaging in surveys. Many of the respondents actually stated that this was the first survey they took part in. Since the survey was done online, almost all questions were set to be compulsory. Thus, there were no incomplete responses.

The workshop was another way to obtain opinions of professionals. It was designed to allow professionals to discuss the provided list of drivers and barriers and rate them using the Likert scale. The difference between this approach and the online survey was apparent as respondents had a chance to discuss the items in their respective groups (3-4 respondents per group) and provide more refined answers. The fact that one author of the study was mediating 
the workshop enabled a qualitative understanding of the choices made by the participants to be gained. In total, 25 professionals participated in the workshop.

TwoStep Clustering Component (TSCC) was used to classify all the responses into a few representative clusters with a significant accuracy which represents the ratings of the stakeholders engaged (Park and Baik, 2006; Pan and Li, 2016). TSCC is able to handle both continuous and categorical variables by extending the model-based distance measure. One of the advantages of this clustering algorithm is its usability in the cases where both continuous and categorical variables exist in data sets; also, it allows the number of clusters to be determined automatically (SPSS, 2001).

However, collection of the priority information only from a particular stakeholder group having similar background and experience (e.g. construction professionals either from the local/regional market or from extant literature) may result in biased decisions (Okoli and Pawlowski, 2004; Hurmekoski et al., 2018). Their information can be reliable but strongly dependent on personal skill and experiences, and implicitly local and/or explicitly global contexts. The suggested method deals with this identified problem by extending the scope of the poll with divergent expert opinions via the Delphi method which consolidates the results of the stakeholder surveys and the expert opinion workshop (Atanda, 2019, Luiz et al., 2018; Kamari et al., 2017; Hugé et al., 2010). The overall purpose of using the Delphi technique is to consolidate the opinions of the stakeholders which were collected by different methods. In the first round of the Delphi stage, the stakeholder priority lists along with their indicator ratings and the underlying assumptions were provided to the IPE. IPE members have their own research groups working in a similar area and they voluntarily agreed to participate in the research. They were asked to revise the lists and merge them into one list in the light of the decisions made by their own group of experts. After all the IPE sorted lists were returned, the agreed upon priorities for the items provided were ranked and a new list was formed with agreed and non-agreed items. After that, it was sent back to the IPE for the second round, and they were asked to revise only the non-agreed items. The rounds were continued until a general agreement was reached (it was 3 rounds in our case) on one final priority list of drivers and barriers. This became our context-oriented Decision Support System (DSS) information for SC in Kazakhstan. 


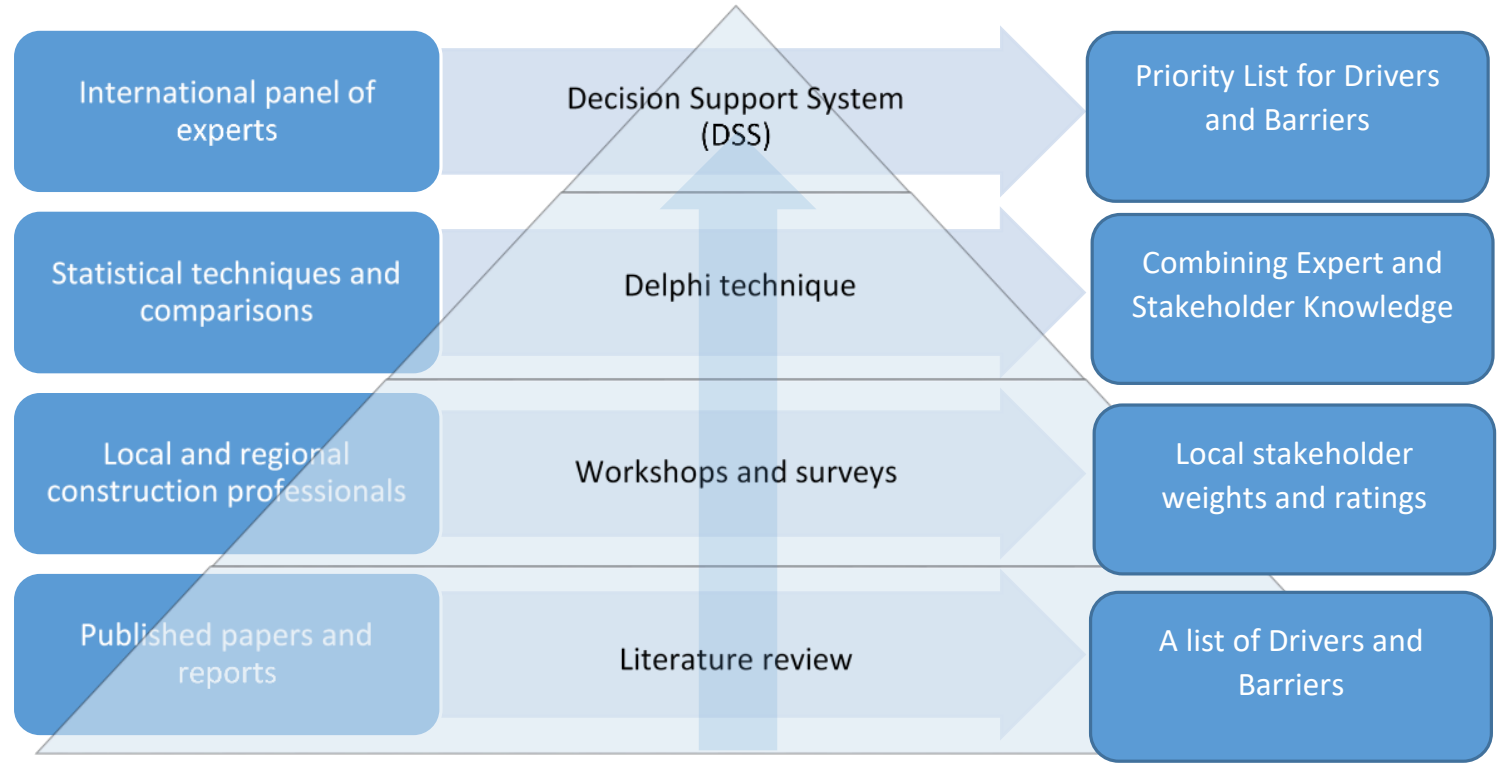

Figure 1. SOPP with a DSS cap

\section{Results}

Formations of the stakeholder representative priority lists

All the survey results were statistically classified during the second stage of the study. At that point, a handful of priority lists, namely clusters, ( 2 in both cases) were classified. In addition to these stakeholder representative priority lists, another set of additional priority lists, that were an outcome of the construction professionals' workshop, was obtained. Mean values and standard deviations of the extracted clusters for the drivers and barriers are given in Table 3 and Table 4, respectively.

Table 3: Stakeholder representative priority lists ratings for SC drivers

\begin{tabular}{|l|l|l|l|l|}
\hline Drivers & Cluster 1 & Cluster 2 & $\begin{array}{l}\text { Workshop } \\
\text { Groups }\end{array}$ & Combined \\
\hline Energy efficiency/conservation & $4.65 \pm 0.74$ & $3.57 \pm 1.36$ & $4.6 \pm 0.89$ & $4.3 \pm 1.1$ \\
\hline Material/resource efficiency & $4.73 \pm 0.51$ & $3.67 \pm 0.97$ & $4.2 \pm 0.84$ & $4.35 \pm 0.85$ \\
\hline Water efficiency & $4.65 \pm 0.58$ & $3.52 \pm 1.08$ & $4.2 \pm 1.1$ & $4.26 \pm 0.95$ \\
\hline Efficient use of land & $4.58 \pm 0.81$ & $3.43 \pm 1.12$ & $1.8 \pm 0.84$ & $4 \pm 1.23$ \\
\hline Waste reduction/management & $4.9 \pm 0.3$ & $3.43 \pm 1.16$ & $4.2 \pm 0.84$ & $4.38 \pm 0.99$ \\
\hline Atmosphere & $4.83 \pm 0.45$ & $3.19 \pm 1.33$ & $4.2 \pm 0.84$ & $4.26 \pm 1.13$ \\
\hline $\begin{array}{l}\text { Indoor environmental } \\
\text { quality/comfort }\end{array}$ & $4.8 \pm 0.46$ & $3.86 \pm 1.2$ & $3.2 \pm 1.3$ & $4.38 \pm 0.99$ \\
\hline Preserving the ecology & $4.9 \pm 0.3$ & $3.1 \pm 1.22$ & $4.4 \pm 0.89$ & $4.29 \pm 1.12$ \\
\hline Competitive construction industry & $4.65 \pm 0.58$ & $2.76 \pm 1.09$ & $3.6 \pm 0.89$ & $3.97 \pm 1.18$ \\
\hline Life cycle cost & $4.65 \pm 0.53$ & $2.52 \pm 1.17$ & $4 \pm 1.22$ & $3.92 \pm 1.28$ \\
\hline
\end{tabular}




\begin{tabular}{|l|l|l|l|l|}
\hline Affordable construction material & $4.5 \pm 0.78$ & $3 \pm 1.26$ & $4 \pm 0$ & $3.98 \pm 1.16$ \\
\hline Support of national economy & $4.48 \pm 0.88$ & $2.76 \pm 1$ & $3.4 \pm 1.67$ & $3.85 \pm 1.26$ \\
\hline Commercial viability & $4.35 \pm 0.95$ & $3.05 \pm 1.16$ & $4.4 \pm 0.55$ & $3.94 \pm 1.16$ \\
\hline $\begin{array}{l}\text { Improvement in industry } \\
\text { image/reputation }\end{array}$ & $4.45 \pm 0.93$ & $3.19 \pm 1.03$ & $3.8 \pm 1.64$ & $4 \pm 1.16$ \\
\hline Enhanced health and safety & $4.7 \pm 0.76$ & $3.48 \pm 1.17$ & $4.6 \pm 0.89$ & $4.3 \pm 1.07$ \\
\hline $\begin{array}{l}\text { Collaborative working } \\
\text { environment }\end{array}$ & $4.6 \pm 0.78$ & $3.38 \pm 1.12$ & $3 \pm 1.22$ & $4.09 \pm 1.12$ \\
\hline Preserving culture/heritage & $4.43 \pm 1.03$ & $2.86 \pm 1.15$ & $2.6 \pm 0.89$ & $3.79 \pm 1.32$ \\
\hline Secure industry & $4.43 \pm 0.87$ & $2.95 \pm 1.12$ & $4 \pm 1.22$ & $3.92 \pm 1.18$ \\
\hline Community friendly industry & $4.6 \pm 0.67$ & $3.05 \pm 1.2$ & $3.6 \pm 1.14$ & $4.03 \pm 1.15$ \\
\hline
\end{tabular}

Table 4: Stakeholder representative priority lists ratings for SC barriers

\begin{tabular}{|l|l|l|l|l|}
\hline Barriers & Cluster 1 & Cluster 2 & $\begin{array}{l}\text { Workshop } \\
\text { Groups }\end{array}$ & Combined \\
\hline Lack of promotion by government & $4.47 \pm 0.74$ & $2.94 \pm 1.35$ & $3 \pm 1.22$ & $3.94 \pm 1.2$ \\
\hline Lack of regulations and policies & $4.6 \pm 0.58$ & $2.67 \pm 1.14$ & $3.8 \pm 1.3$ & $4.02 \pm 1.18$ \\
\hline Lack of government incentives & $4.47 \pm 0.74$ & $2.83 \pm 1.04$ & $3.2 \pm 0.84$ & $3.92 \pm 1.11$ \\
\hline Lack of enforcement & $4.21 \pm 0.97$ & $2.44 \pm 0.86$ & $4 \pm 1$ & $3.71 \pm 1.21$ \\
\hline High cost of sustainable options & $4.58 \pm 0.88$ & $3.22 \pm 1.26$ & $4.8 \pm 0.45$ & $4.23 \pm 1.15$ \\
\hline Longer pay back periods & $4.58 \pm 0.66$ & $3.22 \pm 1.44$ & $4 \pm 0.71$ & $4.17 \pm 1.1$ \\
\hline $\begin{array}{l}\text { Economic needs are given higher } \\
\text { priority }\end{array}$ & $4.53 \pm 0.8$ & $2.94 \pm 0.94$ & $3.4 \pm 1.14$ & $4.02 \pm 1.12$ \\
\hline Lack of financial incentives & $4.4 \pm 0.82$ & $2.83 \pm 1.2$ & $3.4 \pm 1.14$ & $3.89 \pm 1.18$ \\
\hline $\begin{array}{l}\text { Limited understanding from } \\
\text { stakeholders }\end{array}$ & $4.51 \pm 0.67$ & $2.5 \pm 1.1$ & $2.8 \pm 0.84$ & $3.83 \pm 1.24$ \\
\hline $\begin{array}{l}\text { Knowledge on benefits of } \\
\text { sustainable is limited }\end{array}$ & $4.63 \pm 0.66$ & $2.83 \pm 1.29$ & $3 \pm 1.22$ & $4.02 \pm 1.23$ \\
\hline $\begin{array}{l}\text { Knowledge on sustainable } \\
\text { technologies is limited }\end{array}$ & $4.58 \pm 0.63$ & $2.61 \pm 1.24$ & $3.2 \pm 0.84$ & $3.94 \pm 1.23$ \\
\hline $\begin{array}{l}\text { Lack of green suppliers and } \\
\text { limited information }\end{array}$ & $4.3 \pm 0.77$ & $2.94 \pm 1.26$ & $2.4 \pm 1.14$ & $3.79 \pm 1.18$ \\
\hline Lack of demonstration projects & $3.93 \pm 1.03$ & $3.11 \pm 1.23$ & $2.4 \pm 1.67$ & $3.59 \pm 1.23$ \\
\hline $\begin{array}{l}\text { Lack of education and training for } \\
\text { construction professionals }\end{array}$ & $4.51 \pm 0.67$ & $3.06 \pm 1.3$ & $3.6 \pm 1.34$ & $4.05 \pm 1.13$ \\
\hline $\begin{array}{l}\text { Lack of competence in } \\
\text { sustainability }\end{array}$ & $4.37 \pm 0.79$ & $2.83 \pm 1.2$ & $4.6 \pm 0.55$ & $3.97 \pm 1.14$ \\
\hline $\begin{array}{l}\text { Lack of professional } \\
\text { capabilities/designers }\end{array}$ & $4.16 \pm 0.97$ & $2.72 \pm 1.07$ & $4 \pm 0.71$ & $3.76 \pm 1.16$ \\
\hline $\begin{array}{l}\text { Less priority is given to } \\
\text { sustainability during the bidding } \\
\text { stage }\end{array}$ & $4.44 \pm 0.8$ & $3 \pm 1.37$ & $4.2 \pm 0.45$ & $4.03 \pm 1.15$ \\
\hline Lack of clients' interest & $4.44 \pm 0.67$ & $3 \pm 1.08$ & $3.6 \pm 0.89$ & $3.98 \pm 1.03$ \\
\hline $\begin{array}{l}\text { Reluctance to shift from the } \\
\text { conventional methods }\end{array}$ & $2.61 \pm 1.2$ & $3.8 \pm 1.3$ & $3.65 \pm 1.23$ \\
\hline
\end{tabular}


The role, work, experience and awareness are the nominal parameters collected from the respondents. They were also analyzed and their contributions into the clusters are reported in Table 5.

Table 5: Stakeholder contributions into the clusters

\begin{tabular}{|c|c|c|c|c|c|c|c|c|}
\hline \multirow{12}{*}{ 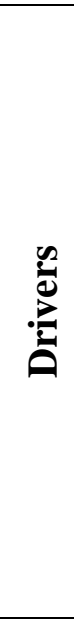 } & \multicolumn{2}{|l|}{ Role } & Architect & Controller & Director & Engineer & Manager & Other \\
\hline & \multirow[t]{2}{*}{ Cluster } & 1 & $7.5 \%$ & $10.0 \%$ & $15.0 \%$ & $20.0 \%$ & $30.0 \%$ & $17.5 \%$ \\
\hline & & 2 & $4.8 \%$ & $0.0 \%$ & $9.5 \%$ & $42.9 \%$ & $33.3 \%$ & $9.5 \%$ \\
\hline & \multicolumn{2}{|l|}{ Work } & Client & Consultant & Contractor & Gov. & Subcont & \\
\hline & \multirow[t]{2}{*}{ Cluster } & 1 & $40.0 \%$ & $17.5 \%$ & $22.5 \%$ & $12.5 \%$ & $7.5 \%$ & \\
\hline & & 2 & $38.1 \%$ & $23.8 \%$ & $14.3 \%$ & $14.3 \%$ & $9.5 \%$ & \\
\hline & \multicolumn{2}{|c|}{ Experience } & $<5$ years & $5-7$ years & 5-7 years & $7-10$ years & $>15$ years & \\
\hline & \multirow[t]{2}{*}{ Cluster } & 1 & $45.0 \%$ & $10.0 \%$ & $10.0 \%$ & $17.5 \%$ & $5.0 \%$ & \\
\hline & & 2 & $57.1 \%$ & $4.8 \%$ & $4.8 \%$ & $19.0 \%$ & $4.8 \%$ & \\
\hline & \multicolumn{2}{|c|}{ Awareness } & Heard & No & Yes & & & \\
\hline & \multirow[t]{2}{*}{ Cluster } & 1 & $30.0 \%$ & $7.5 \%$ & $62.5 \%$ & & & \\
\hline & & 2 & $33.3 \%$ & $4.8 \%$ & $61.9 \%$ & & & \\
\hline \multirow{12}{*}{ 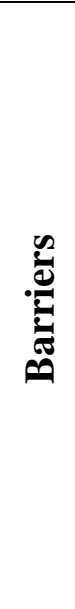 } & Role & & Architect & Controller & Director & Engineer & Manager & Other \\
\hline & \multirow{2}{*}{ Cluster } & 1 & $2.3 \%$ & $7.0 \%$ & $14.0 \%$ & $25.6 \%$ & $30.2 \%$ & $20.9 \%$ \\
\hline & & 2 & $16.7 \%$ & $5.6 \%$ & $11.1 \%$ & $33.3 \%$ & $33.3 \%$ & $0.0 \%$ \\
\hline & Work & & Client & Consultant & Contractor & Gov & Subcont & \\
\hline & \multirow[t]{2}{*}{ Cluster } & 1 & $46.5 \%$ & $18.6 \%$ & $16.3 \%$ & $14.0 \%$ & $4.7 \%$ & \\
\hline & & 2 & $22.2 \%$ & $22.2 \%$ & $27.8 \%$ & $11.1 \%$ & $16.7 \%$ & \\
\hline & \multicolumn{2}{|c|}{ Experience } & $<5$ years & 5-7 years & 5-7 years & $7-10$ years & $>15$ years & \\
\hline & \multirow[t]{2}{*}{ Cluster } & 1 & $53.5 \%$ & $9.3 \%$ & $23.3 \%$ & $14.0 \%$ & $0.0 \%$ & \\
\hline & & 2 & $38.9 \%$ & $5.6 \%$ & $5.6 \%$ & $33.3 \%$ & $16.7 \%$ & \\
\hline & \multicolumn{2}{|c|}{ Awareness } & Heard & No & Yes & & & \\
\hline & \multirow[t]{2}{*}{ Cluster } & 1 & $34.9 \%$ & $4.7 \%$ & $60.5 \%$ & & & \\
\hline & & 2 & $22.2 \%$ & $11.1 \%$ & $66.7 \%$ & & & \\
\hline
\end{tabular}

In terms of sorting or prioritization there are significant differences in clusters; however, the most significant difference is obtained with the given scores for all the items. Cluster 2 scores are significantly lower for all the cases; drivers range [2.52-3.86] and barriers range [2.44-3.22], while Cluster 1 scores had higher levels of estimates [4.35 - 4.90] and [3.93-4.63], respectively. It seems that the clustering algorithm separated the cases based on their scoring ranges. In addition to that, the workshop group evaluations provided more fluctuating scoring in the range of [1.80 - 4.60] and [2.40-4.80], respectively.

There is strong disagreement in the rankings in some of the priority lists, which shows some significant differences between the groups. For instance, only one item (Material/resource efficiency) was sorted in the top five items in all the lists, and even, some 
top-ranked items in one list, are listed in the bottom levels of the other lists (e.g. Indoor environmental quality/comfort).

The results indicate that the rating numbers are subjective and show significant variations according to respondents' profile and data collection methodology. For example, Cluster 1 in the priority list is largely clients (66.7\%) and contractors (75.0\%) who are mostly controllers and directors with midlevel experience (5-15 years) (Table 5), a representative group of experienced construction company managers who tend to give higher scores in each indicator. Less experienced engineers working for the government had a tendency to give lower level scores in Cluster 2.

Our findings also revealed that significantly different results were obtained by employing different tools (online surveys vs group workshops) due to their differences in procedures. In the survey method, respondents did not have in-person expert explanations but written descriptions), and moreover, they had the questions in an order without knowing what the next item was. On the other hand, workshop groups had a brief expert explanation prior to their engagement, they had a chance to ask questions, and they got all the items in a single page which provided a higher level of understanding to make pairwise multiple comparisons by checking all the items during the given time. As a result, online and workshop based local expert surveying methods ended up with different results in the ratings. It can be easily speculated that it is very likely to get different sets of rating scores with different procedures in every new challenge.

All the above discussions and results confirm our hypothesis which suggests that collecting priority information from only local experts using online surveys or workshop methods may have serious limitations. Such results need to be consolidated by a higher level expert knowledge system, e.g. the IPEs in our case, as suggested by the last stage of our proposed methodology. The following section extended the consolidated results.

\section{Consolidation of the priority lists}

The final stage of the data analysis was carried out with the help of the IPE. The IPE members, independently from each other, merged the three priority lists provided. In total, three iterations were carried out to come up with the consolidated lists of drivers and barriers of the construction industry of Kazakhstan (Tables 6 and 7, respectively). The consolidated lists present ranked drivers and barriers according to their priorities. Depending on the 
position in the lists, the four Priority Levels (PLs) were assigned to the drivers and barriers, namely Extensive, Significant, Moderate and Minor from Level 4 to Level 1.

Table 6: Consolidated list for the drivers

\begin{tabular}{ll} 
Priority & Consolidated list for the drivers \\
\hline Extensive & Energy efficiency/conservation \\
& Material/resource efficiency \\
& Enhanced health and safety \\
& Preserving ecology \\
& Waste reduction/management \\
\hline Significant & Indoor environmental quality/comfort \\
& Water efficiency \\
& Community friendly industry \\
& Atmosphere \\
& Affordable construction material \\
\hline Moderate & Life cycle cost \\
& Improvement in industry image/reputation \\
& Collaborative working environment \\
& Commercial viability \\
Competitive construction industry \\
\hline Minor & Secure industry \\
& Support of national economy \\
& Preserving culture/heritage \\
Efficiency use of land
\end{tabular}

Table 7: Consolidated list for the barriers

\begin{tabular}{ll} 
Priority & Consolidated list for the barriers \\
\hline Extensive & The higher cost of sustainable building option \\
& Longer payback periods \\
& Lack of professional expertise in sustainability \\
& Sustainability criteria is not considered in the bid evaluation \\
& Limited knowledge on clear benefits of sustainable practices \\
\hline Significant & Higher priority is given to economic needs \\
& Lack of training and education for professionals \\
& Lack of promotion by government \\
& Lack of government incentives \\
& Resistance to change from the use of traditional methods \\
\hline Moderate & Lack of knowledge on sustainable technologies \\
& Lack of codes and regulations that cover sustainable procurement \\
& Lack of financial incentives \\
& Shortage in green suppliers and information \\
& Lack of professional capabilities/designers \\
\hline Minor & Limited understanding from stakeholders \\
& Lack of enforcement \\
& Lack of demonstration projects
\end{tabular}


As mentioned in the previous section, two cluster groups and the group workshop results were not similar. In the process of consolidation, the IPE aimed to streamline the priority levels of respective drivers and barriers based on a comparative analysis. This process actually allowed experts to merge the three priority lists based on their experience and knowledge of the subject matter. During the consolidation, it was evident that some of the high or low priority items from one list (e.g. Cluster 1) were in lower or higher positions in the final consolidated list. The study aimed to see to what extent those changes were significant. In order to assess the significance of changes, the study investigated the level of change by estimating the difference between the final and initial priority levels. So if one item from Cluster 1, for example, was initially falling under Extensive Priority level (Level 4) but ended up in the Moderate Priority level (Level 2) in the consolidated list, the extent of the change would be equal to two - meaning that the change is significant.

In the case of drivers from Cluster 1, the number of items which had no change in the priority level were 7 , a change of one level were 12, and a change of two levels were 0 . This is a good outcome as the consolidated list is relatively similar to this cluster's results. In case of drivers from Cluster 2, these values were 7, 10 and 2 (Efficient use of land and Preserving the ecology) respectively. For the group workshop, these values were 11, 6 and 2 (Commercial viability and Indoor environmental quality/comfort) respectively. In the case of barriers from Cluster 1, the values were 12, 2 and 5 (Lack of codes and regulations that cover sustainable procurement; Lack of knowledge on sustainable technologies; Limited understanding from stakeholders; Sustainability criteria is not considered in the bid evaluation; Lack of professional expertise in sustainability); from Cluster 2 the values were 10, 6, 0 (and 3 items had change of three levels - Lack of demonstration projects; Limited knowledge on clear benefits of sustainable practices; Lack of professional expertise in sustainability); from group workshop the values were 10, 6, 1 (Lack of clients' interest), (and 2 items had change of three levels - Lack of enforcement; Limited knowledge on clear benefits of sustainable practices). As it can be seen from the numbers above, in the case of drivers, Cluster 1 had quite a strong similarity to the consolidated list with no items changing position more than one level. At the same time, Cluster 2 and group workshop results had only 2 items changing position 2 levels. In the case of barriers, the situation is slightly different since all the three priority lists had more than one item which changed 2-3 positions. 
Another way to analyze the study results was to split the factors within drivers and barriers into priority levels. Drivers were grouped into environmental, social and economic factors. Barriers, in turn, were grouped into factors such as government, cost, knowledge and information, workforce, client and market. In the case of drivers, it was found that most of the Extensive and Significant drivers are environment related (7 out of 10), the remaining drivers were social ( 2 out of 10 ) and economic ( 1 out of 10). 4 out 5 drivers ranked as Moderate were economic drivers, with 1 out 5 being a social driver. The remaining 4 Minor drivers were 1 environmental, 1 economic and 2 social. It is evident from Table 6 and the data above that most of the extensively important drivers are environment-related ones. This could be explained by the conventional understanding of sustainability metaphors, e.g. a bias to think that is more of an environmental concept, although $60.5 \%$ of respondents stated that they know that sustainability is based on three pillars. In fact, the term sustainability does not have a direct translation in the local language. The closest option is "green", the term that is well connected with ecology. In turn, socio-economic drivers are located in the second half of the table with less priority given.

In case of the barriers, the highest ranked ones are directly related to economic and knowledge related aspects. In fact, 2 out of 5 Extensive barriers are cost related. This is most likely related to the fact that stakeholders tend to believe that a prohibitively high cost of sustainability measures plays a hindering role. These are followed by the government related issues such as lack of government promotion and incentives. 2 out 5 significant barriers were government related. The remaining barriers were spread across the priority levels. This implies that stakeholders believe that sustainable construction is hindered by a set of factors combining the availability of knowledge and information, the issues related to workforce as well as the readiness of clients and the market.

\section{Discussion}

As it can be seen from Table 6, the majority of the most essential drivers of sustainable construction are environment-related. For example, such drivers as "Energy efficiency/conservation, Material/resource efficiency, Preserving ecology, Waste reduction/management, Water efficiency, and Atmosphere" were ranked as the most critical ones. These findings, in fact, can be supported by the results of the previous study by the authors (Tokbolat et al, 2018). In this previous study, all buildings in Kazakhstan, Astana, which was chosen as a representational city, were grouped as "new" and "old" buildings with 
sub-categorization based on their class and materials that were used for construction. The study concluded that within the "new" Economy class, with buildings which were found to be least sustainable, greater attention should be paid to environment-related aspects, particularly to improving the sustainability level using surrounding ecosystems such as land and water. With all "new" buildings regardless of their class it was suggested that attention be paid to waste management and use of materials. In the case of "old" buildings, the highest priority was given to waste management, use of materials, energy consumption, and sustainable use of ecosystems.

In the case of the barriers, the highest ranked ones are primarily related to economic, governmental support and knowledge associated aspects, such as "The higher cost of sustainable building option, Longer payback periods, Lack of professional expertise in sustainability, Sustainability criteria is not considered in the bid evaluation, Limited knowledge on clear benefits of sustainable practices, Higher priority is given to economic needs, Lack of training and education for professionals, Lack of promotion by government, Lack of government incentives". Another study by Tokbolat \& Calay (2015), that attempted to understand the awareness level of sustainability concepts among construction companies and general public in the UK and Kazakhstan, supports the outcomes of the current research confirming that the key barriers of sustainable construction in Kazakhstan are economic, governmental support and knowledge related. The study found that Kazakhstan's construction companies see "economic restrictions, strict regulations, poor awareness of sustainability and a short period focus" as the main barriers of sustainable construction. The same study reported that in the general public's view the main barriers are "a lack of experience and practice of the construction workers, poor legal enforcement, poor understanding of the concept, and economic burdens".

\section{Implications for the Construction Frontline}

In the global perspective, the outcomes of this study would deepen the understanding of the impact of barriers and drivers of sustainable construction in a typical developing country's reality. At the same time, the findings of this research article are of high significance in the local context, particularly for the construction industry of Kazakhstan. As Kazakhstan's government strives to comply with the commitments made in the framework of various sustainability-related international conventions and agreements, such as for example, the Paris Agreement, it rigorously seeks ways to reduce greenhouse gas emissions and at the same time efficiently use its energy resources. The country's construction industry, which is 
among the most significant energy consumers and GHG emitters, is experiencing pressure from the government to be more sustainable than it is now. Therefore, the construction industry would benefit from the outcomes of this study as it suggests the ways to achieve sustainability by identifying and prioritizing respective barriers and drivers. Although, players of Kazakhstan's construction industry tend to refer to various drivers and barriers of sustainability, there was a lack of structured understanding of their impact and their priority level. This study fills this gap. Both the government and construction industry related stakeholders are provided with comprehensive priority lists of barriers and drivers they should address in order to meet the targeted sustainability objectives. These lists are believed to be valuable indicators for decision-making at all levels by respective parties. It is thought that addressing drivers and barriers according to their priority level can be among some of the most effective ways of increasing sustainability levels in the construction industry. However, it must be realized that the priority levels of particular drivers and barriers can change over time due to changing economic and political reality, technological advancement and increasing awareness of sustainability and pressing needs of climate change mitigation and adaptation.

\section{Conclusions}

Sufficient evidence shows that the past two decades have witnessed increased concern for the devastating impact of the construction industry on our eco-system and its depletion of natural resources. This has increased promotion of sustainable building technologies and practices to reduce natural resource consumption, and the threatening environmental impact of the built environment. These practices seem to be increasingly adopted as long as the inhibiting barriers are overcome. As in other developing countries, Kazakhstan has been experiencing a rapid urbanization, where the construction industry undertakes a crucial role. Therefore, there is a need to investigate factors that are potential triggers and barriers inhibiting the adoption of SC in the local context of Kazakhstan.

This study suggests an original methodological perspective to consolidate and prioritize stakeholder opinions gathered from local experts to achieve more consistent decisions. It can be concluded that online surveying methods in stakeholder opining research had some drawbacks which can possibly lead to less reliable data. The lack of a trained interviewer or in person expert explanations to clarify is the most significant drawback that was experienced in this study. A better tool might be 'one to one interviews' which could 
eliminate this drawback, but still allow subjective results to be obtained. A structured workshop with stakeholders who have different levels of experience and background is a better solution, although it needs to be guided by an expert. . It is suggested that external experts be employed, e.g. International Panel of Experts, to refine the results obtained from the earlier mentioned tools.

The study has identified the priority lists for drivers and barriers for implementation in the context of Kazakhstan. Consolidated lists of drivers and barriers suggest their respective significance. These lists are thought to be useful indicators for stakeholders to use throughout their decision-making processes. It is believed that labelling the respective drivers and barriers according to their priority level would help to effectively improve the issues of sustainable construction. Specifically, in the case of SC drivers, the utmost importance should be given to aspects related to environmental issues in Kazakhstan. For example, Energy efficiency/conservation or Material/recourse efficiency are the highest ranked drivers of SC. There is also a high level of agreement that drivers related to social sustainability are significant compared to, for example, economic drivers. Drivers such as Enhanced health and safety, Indoor environmental quality/comfort and Community friendly industry are some of the highest ranked social drivers. It can be concluded that for SC to be advanced in Kazakhstan, in the opinion of stakeholders as well as the International Panel of Experts, aspects related to environment and social reality can be the strongest motivating force. This can be explained by the fact that although Kazakhstan is a relatively wealthy country with significant investments in the construction industry, there is no significant change in the level of sustainability, so the financial aspect does not seem to be changing the sustainabilityrelated paradigm in the country.

Opposite to this, it can be observed that a great portion of SC barriers are actually related to economic aspects. In fact, barriers such as Higher cost of sustainable building option, Longer payback periods, Sustainability criteria is not considered in the bid evaluation, Higher priority is given to economic needs, are all ranked as very significant aspects. These are followed by government as well as awareness/education related barriers. For example, Lack of professional expertise in sustainability, Limited knowledge on clear benefits of sustainable practices, Lack of training and education for professionals, Lack of promotion by government, Lack of government incentives, are all ranked as significant barriers. 
The construction industry and the government would benefit from addressing the significant drivers and barriers. However, to address the issues of SC, all the drivers and barriers should be addressed at a system level since the concept of sustainability, in general, requires complex solutions and simultaneous transformation of all aspects.

\section{Acknowledgment}

Mr. Farnush Nazipov, a student from Nazarbayev University, is acknowledged for his assistance in data collection. The support of Nazarbayev University and Ara Institute of Canterbury is acknowledged.

\section{References}

Abidin, N. Z., \& Powmya, A. (2014). Perceptions on motivating factors and future prospects of green construction in Oman. Journal of Sustainable Development, 7(5), 231-239.

Ahn, Y. H., Pearce, A. R., Wang, Y. and Wang, G. (2013). Drivers and barriers of sustainable design and construction: The perception of green building experience. International Journal of Sustainable Building Technology and Urban Development, 4(1), 35-45.

Akadiri, P.O., Chinyio, E.A. and Olomolaiye, P.O. (2012). Design of a sustainable building: A conceptual framework for implementing sustainability in the building sector. Buildings, $2,126-152$.

AlSanad, S. (2015). Awareness, drivers, actions, and barriers of sustainable construction in Kuwait. Procedia Engineering, 118, 969-983.

Ametepey, O., Aigbavboa, C. and Ansah, K. (2015). Barriers to successful implementation of sustainable construction in the Ghanaian construction industry. Procedia Manufacturing, 3, 1682-1689.

Atanda, J.O. (2019). Developing a social sustainability assessment framework. Sustainable Cities and Society, 44, 237-252.

Boyle, T. and McGuirk, P. (2012). The decentred firm and the adoption of sustainable office space in Sydney, Australia. Australian Geographer, 43(4), 393-410.

Dahiru, D., Dania, A.A. and Adejoh, A. (2014). An investigation into the prospects of green building practice in Nigeria. Journal of Sustainable Development, 7(6), 158-167.

de Souza Dutra, C. T., Rohan, U., Branco, R. R., Chinelli, C. K., de Araujo, A. J. V. B. and Soares, C. A. P. (2017). Barriers and challenges to the sustainability requirements implementation in public procurement of engineering works and services. Open Journal of Civil Engineering, 7(1), 1-13. 
Djokoto, S. D., Dadzie, J. and Ohemeng-Ababio, E. (2014). Barriers to sustainable construction in the Ghanaian construction industry: consultants' perspectives. Journal of Sustainable Development, 7(1), 134-143.

Durdyev, S., Ismail, S., Ihtiyar, A., Syazwani Abu Bakar, N. F. and Darko, A. (2018b). A partial least squares structural equation modeling (PLS-SEM) of barriers to sustainable construction in Malaysia. Journal of Cleaner Production, 204, 564-572.

Durdyev, S., Zavadskas, E. K., Thurnell, D., Banaitis, A. and Ihtiyar, A. (2018b). Sustainable construction industry in Cambodia: Awareness, drivers and barriers. Sustainability, 10(2), 392.

Durdyev, S. and Ismail, S. (2016). On-site construction productivity in Malaysian infrastructure projects. Structural Survey, 34(4/5), 446-462.

Chan, E. H. W., Qian, Q. K. and Lam, P. T. I. (2009). The market for green building in developed Asian cities - the perspectives of building designers, Energy Policy, 37(8), 3061-3070.

Evans, M. (2006). At the interface between theory and practice - policy transfer and lesson drawing. Public Administration, 84(2), 479-489.

Gou, Z., Lau, S. S. Y. and Prasad, D. (2013). Market readiness and policy implications for green buildings: case study from Hong Kong. Journal of Green Building, 8(2), 162-173.

Häkkinen, T. and Belloni, K. (2011). Barriers and drivers for sustainable building. Building Research and Information, 39(3), 239-255.

Hugé, J., Le Trinh, H., Hai, P. H., Kuilman, J. and Hens, L. (2010). Sustainability indicators for clean development mechanism projects in Vietnam. Environment Development and Sustainability, 12 (4), 561-571.

Huovila, P. and Koskela, L. (1998). Contribution of the principles of lean construction to meet the challenges of sustainable development. 6th Annual Conference of the International Group for Lean Construction. Guarujá, Brazil, 13-15 Aug 1998.

Hurmekoski, E., Pykäläinen, J. and Hetemäki, L. (2018). Long-term targets for green building: Explorative Delphi backcasting study on wood-frame multi-story construction in Finland. Journal of Cleaner Production, 172, 3644-3654.

Kamari, A., Corrao, R. and Kirkegaard, P.H. (2017). Sustainability focused decision-making in building renovation. International Journal of Sustainable Built Environment, 6 (2), 330350. 
Li, X., Strezov, V. and Amati, M. (2013). A qualitative study of motivation and influences for academic green building developments in Australian universities. Journal of Green Building, 8(3), 166-183.

Luiz A., Silveira, B.J., Vasconcellos, E., Guedes, L.V., Guedes, L.F.A. and Costa, R.M. (2018). Technology roadmapping: A methodological proposition to refine Delphi results. Technological Forecasting and Social Change, 126, 194-206.

Luthra, S., Kumar, S., Garg, D. and Haleem, A. (2015). Barriers to renewable/sustainable energy technologies adoption: Indian perspective. Renewable and Sustainable Energy Reviews, 41, 762-776.

Manoliadis, O., Tsolas, I. and Nakou, A. (2006). Sustainable construction and drivers of change in Greece: A Delphi study. Construction Management and Economics, 24(2), 113120 .

Martek, I., Hosseini, M. R., Shrestha, A., Edwards, D.J. and Durdyev, S. (2019). Barriers inhibiting the transition to sustainability within the Australian construction industry: An investigation of technical and social interactions. Journal of Cleaner Production, 211, 281-292.

Martens, M. L. and Carvalho, M. M. (2016). The challenge of introducing sustainability into project management function: multiple-case studies. Journal of Cleaner Production, 20, $29-40$.

Mondor, C., Hockley, S. and Deal, D. (2013). The David Lawrence convention center: how green building design and operations can save money, drive local economic opportunity, and transform an industry. Journal of Green Building, 8(1), 28-43.

Ogungbile A. J. and Oke A. E. (2019). Sustainable Construction Practices in West African Countries. In: Motoasca E., Agarwal A., Breesch H. (eds) Energy Sustainability in Built and Urban Environments. Energy, Environment, and Sustainability. Springer, Singapore

Okoli, C. and Pawlowski, S. D. (2004). The Delphi method as a research tool: an example, design considerations and applications. Information \& Management, 42 (1) 15-29.

OECD, (2015). Going green: best practices for sustainable procurement. Retrieved on December 13, 2017 from: https://www.oecd.org/gov/ethics/Going_Green_Best Practices_for_Sustainable_Procurement.pdf.

Pan, W. and Li, K. (2016). Clusters and exemplars of buildings towards zero carbon. Building and Environment, 104, 92-101.

Park, H.S. and Baik, D.K. (2006). A study for control of client value using cluster analysis. Journal of Network and Computer Applications, 29 (4), 262-276. 
Potbhare, V., Syal, M. and Korkmaz, S. (2009). Adoption of green building guidelines in developing countries based on US and India experiences. Journal of Green Building, 4(2), 158-174.

Qi, G. Y., Shen, L. Y., Zeng, S. X. and Jorge, O. J. (2010). The drivers for contractors' green innovation: An industry perspective. Journal of Cleaner Production, 18(14), 1358-1365.

Rock, S., Hosseini, M. R.,

Sev, A. (2009). How can the construction industry contribute to sustainable development? A conceptual framework. Sustainable Development, 17(3), 161-173.

SPSS (2001). The SPSS TwoStep Cluster Component. Retrieved on November 1, 2018 from: https://www.spss.ch/upload/1122644952_The\%20SPSS\%20TwoStep\%20Cluster\%20Com ponent.pdf

Tokbolat, S. and Calay R.(2015). Residential Construction Sustainability in the UK and Prospects of Knowledge Transfer to Kazakhstan. Journal of Sustainable Development, Vol. 8, No. 9

Tokbolat, S., Karaca, F., Durdyev, S., Nazipov F. and Aidyngaliyev I.(2018). Assessment of green practices inresidential buildings: A survey based empirical study of residents in Kazakhstan. Sustainability, 10(12), 4383

Williams, K. and Dair, C. (2007). What is stopping sustainable building in England? Barriers experienced by stakeholders in delivering sustainable developments. Sustainable Development, 15(3), 135-147.

Wong, J. M. W., Ng, S. T. and Chan, A. P. C. (2010). Strategic planning for the sustainable development of the construction industry in Hong Kong. Habitat International, 34, 256263.

Zainul-Abidin, N. (2010). Investigating the awareness and application of sustainable construction concept by Malaysian developers. Habitat International, 34, 421-426.

Zhang, X., Shen, L., Tam, V. W. and Lee, W. W. Y. (2012). Barriers to implement extensive green roof systems: A Hong Kong study. Renewable and Sustainable Energy Reviews, 16(1), 314-319.

Zolfani, S. H., Pourhossein, M., Yazdani, M. and Zavadskas, E. K. (2018). Evaluating construction projects of hotels based on environmental sustainability with MCDM framework. Alexandria Engineering Journal, 57(1), 357-365. 